\title{
The Relations between Hope and Subjective Well-Being: a Literature Overview and Empirical Analysis
}

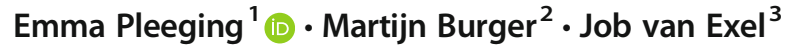

Received: 4 June 2019 / Accepted: 3 December 2019/ Published online: 20 December 2019

(C) The Author(s) 2019

\begin{abstract}
How we perceive the future can greatly affect how we feel in the present. Even a currently positive situation is hard to bear when we know the future will be grim. Indeed, previous research has found that more hopeful people are happier. However, both hope and subjective well-being are multidimensional concepts comprising emotion (i.e., anticipation and affect), cognition (expectation and satisfaction) and, to some degree, motivation. Since most studies include only one dimension of hope and subjective well-being, little is known about how different aspects of hope relate to different aspects of subjective well-being. This study aims to gain insight into these relationships by providing an overview of the existing empirical literature on hope and subjective well-being. Subsequently, cross-sectional data of a representative sample of the American population are used to further examine the relationship between hope and subjective well-being. Our findings from both the literature and our empirical analysis show that positive expectations are only weakly associated with all domains of subjective well-being, whereas cognitive and emotional hope are most strongly related to subjective well-being. This finding indicates that the more passive characteristics of positive expectations have less of an impact on subjective well-being than a more agentic hopeful disposition.
\end{abstract}

Keywords Hope $\cdot$ Subjective well-being $\cdot$ Expectations $\cdot$ Life satisfaction $\cdot$ Affect

Emma Pleeging

pleeging@ese.eur.nl

1 Erasmus Happiness Economics Research Organisation, Erasmus University Rotterdam, Burgermeester Oudlaan 50, 3000 DR Rotterdam, The Netherlands

2 Erasmus Happiness Economics Research Organisation and Department of Applied Economics, Erasmus School of Economics, Erasmus University Rotterdam, Rotterdam, The Netherlands

3 Erasmus School of Health Policy \& Management and Department of Applied Economics, Erasmus School of Economics, Erasmus University Rotterdam, Rotterdam, The Netherlands 


\section{Introduction}

Hope and subjective well-being are closely connected (Bailey et al. 2007). A hopeful disposition usually makes us feel happier, and feeling well often strengthens our hope for a good future. However, both hope and subjective well-being can take different forms, and the relationship between hope and subjective well-being is sometimes ambiguous. Hope, for example, can also be used as a defence mechanism by unhappy people in times of crisis, and false hope does not contribute to a happy life. Both hope and happiness are multidimensional concepts that are conceptualized differently in varying scientific disciplines and can be experienced in different 'modes' in daily life (Webb 2007). As such, even though we know that hope and happiness are generally positively related, we do not yet know how different aspects of these concepts, e.g., hope as an expectation, emotion or thought-pattern and happiness as life satisfaction or positive affect, are related. These unknowns impede our understanding and use of these powerful feelings, since we cannot infer whether different types of hope and subjective wellbeing are related in a similar fashion. As such, it is for example difficult to extrapolate findings from one discipline or study to another. However, understanding under which circumstances hope translates into subjective well-being can help us understand the determinants and mechanisms underlying a happy life. Hence, the current article examines the following question: what do we know so far about the relationship between hope and subjective well-being and how can we better understand this complex relationship? Before we can answer this question, we must define hope and subjective well-being.

\section{Hope}

Hope is essentially a strong desire that is actively pursued, while it is uncertain that this desire will be fulfilled (Martin 2011). The probably most well-known theory about hope comes from Rick Snyder (2002). He defines hope as a primarily cognitive, goaloriented pattern of thought in which people come up with different 'pathways' to achieve their goals, remain motivated to follow these pathways, and actively look for alternative pathways to these goals when necessary. According to Snyder, hopeful people are those who are persistent and creative in pursuing their goals. ${ }^{1}$ This line of thinking is also used in organizational psychology, in which hope is seen as a form of psychological capital that helps employees act in a creative, flexible and constructive manner in an organization (Youssef and Luthans 2007; Avey et al. 2011).

Other psychologists emphasize the more emotional side of hope. For example, Fredrickson (2001) sees hope as a psychological force or 'buffer' that provides resilience and helps us deal with stressful and negative situations. In clinical psychology, the frequently used Herth Hope Index (Herth 1992) focuses not only on future expectations and purposeful thinking but also on a general, diffuse sense of 'hopefulness', hope as an experience rather than as an action, and hope aimed at gaining control over emotions rather than over external circumstances. The hopelessness scale of Aaron

\footnotetext{
${ }^{1}$ In this sense, the 'agency' dimension of hope is related to self-efficacy, i.e. the belief in one's ability to perform certain tasks, yet empirical evidence shows that the two concepts are similar but distinct (Magaletta and Oliver 1999)
} 
Beck et al. (1974), on the other hand, measures negative expectations of the future, a lack of motivation, and the conviction that someone will never be able to achieve his or her goals. This scale is mainly used in studies of psychopathology but is also used to a lesser extent as a divergent validation of subjective well-being (Lucas et al. 1996). Although these approaches also incorporate cognitive components, such as expectations, assumptions and purposeful planning, compared to the hope theory of Snyder, they are much more attuned to the affective side of hope, i.e., the more uncontrollable, spontaneous feelings of arousal and valence accompanying a hopeful state.

Psychology is, however, not the only discipline that has shown interest in hope. References to hope research can also be found in sociology (e.g., Jarymowicz and BarTal 2006; Cohen-Chen, 2014; Petersen and Wilkinson, 2015), economics (e.g. Foster et al. 2012; Frijters et al. 2012; Foster and Frijters 2014; Lybbert and Wydick 2018) philosophy (Webb 2007; Martin 2011), and political science (Bar-Tal 2001; Drahos 2004; Cohen-Chen et al. 2013; Sleat 2013; Boukala and Dimitrakopoulou 2016), although there are clear differences in the research methodology and definitions used. Specifically, many studies in these fields focus more on expectations of improvement or deterioration of the economic, social or personal situation of a country or individual. This operationalization of hope thus often reflects more general, abstract positive expectations and not so much active hope for personal, concrete goals. Moreover, personal expectations or optimism, i.e. the tendency to expect positive things will happen, differ from hope, in the sense that optimism relies on the assumption that things will turn out well, whereas hope is inherently uncertain ${ }^{2}$ (Bailey et al. 2007). Although the concept of hope as used within psychology does include expectations (Snyder 2000), the focus on expectations within social sciences diverges from the psychological approach in two ways. First, hope is inherently agentic and active: when we hope for something, it is uncertain whether we will reach this goal, and we will therefore have to take action if possible. A positive expectation, on the other hand, does not require any action since we already assume that our desire will be fulfilled (or, in the case of negative expectation, that it will not happen). Second, hope is more processoriented. While expectations mainly relate to the goals we expect to achieve, hope also relates to the pathways we come up with to get there (Snyder 2000). These differences are important, as they might influence how the different interpretations of hope relate to subjective well-being.

\section{Subjective Well-Being}

The concept of subjective well-being concerns the appreciation of one's personal condition or one's subjective enjoyment of life as a whole (Diener et al. 1999; Veenhoven 2000). Like hope, happiness has both a cognitive and an emotional component. When we think about our happiness, for example, we may ask ourselves not only whether we feel comfortable throughout the day but also whether we are satisfied with our lives and whether we have achieved the goals we have set for ourselves. The first component concerns intuitive experiences, or our emotional affect

\footnotetext{
${ }^{2}$ Similarly, self-confidence is related to hope, since hope can be more likely to appear when chances of attaining our goals are high. However, hope can also (and often does) arise when future expectations are actually quite grim (Webb 2007).
} 
balance. The second component is more about a cognitive assessment of life as a whole or how we think our current life compares to the most ideal life we have in mind. Together, these components determine - from a hedonistic point of view - overall happiness (Veenhoven 2000; Kashdan et al. 2008).

These different components of happiness do not always go hand in hand and are influenced in different ways by our living conditions. A successful career may well contribute to life satisfaction, while the additional stress creates a more negative emotional balance during the working day. However, it is also possible to feel good throughout the day but not be satisfied with what we have achieved in our lives. For example, a higher income is usually found to increase life satisfaction (Kahneman and Deaton 2010), whereas social contacts mainly lead to a positive emotional balance (Diener et al. 2010a).

\section{The Relationship between Hope and Subjective Well-Being}

Snyder's hope theory assumes that hope leads to higher levels of subjective well-being when we experience success in pursuing our goals. People who are more hopeful are more creative and show more perseverance in pursuing their goals, which in turn could result in higher levels of happiness by gaining more successful experiences (Snyder 2000; Bailey et al. 2007). Another possible explanation for the relationship between hope and subjective well-being is that people who are hopeful see more opportunities and therefore more easily achieve the things that make them satisfied with their life, such as a successful relationship or career. For example, various studies have shown that hope is positively associated with academic (Snyder 2002), professional (Youssef and Luthans 2007) and athletic success (Curry et al. 1997). A third explanation can be found in the broaden-and-build theory, according to which positive emotions contribute to broader subjective well-being because people who feel good are usually more open to new situations, relationships and impressions and therefore gain more experience and skills (Fredrickson 2001). Moreover, positive emotions would ensure that people can respond with more resilience in negative situations and thus experience fewer negative consequences of setbacks (Arampatzi et al. 2019).

Although hope and subjective well-being usually go hand in hand, this connection is not uniform for all different aspects of hope and subjective well-being. In particular, the connection between positive expectations and subjective well-being can be hypothesized to be relatively weak. First, positive expectations of the future generally concern more abstract social developments that lie outside the individual, whereas other forms of hope focus specifically on achieving concrete, personal goals. However, it is precisely these personal goals, for which we are intrinsically motivated, that usually contribute to our happiness (Ryan and Deci 2000). In addition, positive expectations can have a negative effect on happiness if they do not materialize, as those who expect a lot from life will probably be disappointed sooner than others (Greenaway et al. 2016). Moreover, when expectations are focused on acquiring material wealth, this can distract from other aspects of our lives, such as good social relationships. Usually, such a materialistic focus goes hand in hand with diminished well-being (Van Boven 2005). Lastly, an overly optimistic view of the future might diminish well-being if it keeps people from improving a bad situation. This might especially be the case when positive expectations are based on denial of the severity or urgency of problems at hand (Ojala 2012). 
Given the potentially ambiguous relationship between hope and subjective wellbeing, in this paper, we take stock of what we know about the relationship between the different aspects of these concepts. Although the topic has been included in previous meta-analytic reviews (e.g., Avey et al. 2011; Alarcon et al. 2013; Reichard et al. 2013), to the best of our knowledge, this study is the first to include and systematically compare studies from different disciplines, covering both cognitive and emotional aspects of hope and subjective well-being as well as expectations, on top of conducting an empirical study including a diverse set of measures of hope and subjective well-being. The remainder of this paper is organized as follows. We start with a systematic review of the existing literature ("Empirical Literature on Hope and Subjective Well-Being" section), in which we summarize existing empirical evidence, followed by an empirical study ("Empirical Study" section), in which the many faces of hope and happiness are further compared. Section 4 discusses and concludes the paper.

\section{Empirical Literature on Hope and Subjective Well-Being}

\section{Selection of Studies}

In this research, we used the World Database of Happiness to study the existing literature on the relations between hope and happiness. The World Database of Happiness includes studies that examine happiness in terms of subjective enjoyment with life as a whole, also known as 'subjective well-being', 'perceived quality of life' and 'life satisfaction'. Studies are included in this database based on the outcome measure, and the database includes only studies that use valid measures of subjective well-being. Of all publications in the World Database of Happiness, 48 studies concern the topic of hope and subjective well-being. Of these 48 studies, we selected those that were quantitative in nature, reported new findings (to avoid duplicate findings), and reported zero-order correlations. Please note that most studies (especially older studies) report only zero-order correlations, and for comparability, we report only these findings. Quantitative studies that reported regression coefficients but no zero-order correlations, i.e., predominantly economics studies that examined the positive expectations and subjective well-being relationship, were therefore omitted from the review. In total, our review contains 34 different studies and 84 different findings regarding the correlation between hope and subjective well-being. An overview of the studies included in the survey can be found in Appendix A.

\section{Hope and Subjective Well-Being Measures in Empirical Studies}

With regard to hope, we discern three different types of measures that were used in the included studies, capturing three different approaches: the cognitive approach, the emotional approach, and positive expectations.

In the cognitive approach to hope, hope is most often measured using Snyder's Adult Trait Hope Scale (ATHS; Snyder et al., 1991) or the Revised Snyder Hope Scale (RSHS; Shorey et al. 2009). The former scale contains 12 items (of which 4 are used as 
fillers), for which participants have to rate statements such as 'I can think of many ways to get out of a jam' and 'My past experiences have prepared me well for my future'. The scale can be subdivided into two subscales: one for agency and one for pathways. Agency refers to the belief that someone is capable of achieving her or his goals, whereas the pathways subscale refers to the ability to imagine possible routes to these goals (Snyder 2000).

The emotional approach to hope uses instruments aimed at measuring general feelings of hopefulness or hopelessness. Hopefulness, capturing the positive emotional approach to hope, has been measured using the Herth Hope Index (HHI; Herth 1992) ${ }^{3}$ and the Miller Hope Scale (Miller and Powers 1988). The statements that respondents have to rate in the HHI focus on temporality, the future, positive expectations, readiness and interconnectedness. Example statements include 'I have a positive outlook towards life', 'I have deep inner strength', and 'I feel all alone'. Similarly, the Miller Hope Scale focuses on the anticipation of a future good, mutuality, competence, well-being and purpose and includes statements such as "I look forward to an enjoyable future". Hopelessness is captured by the Beck Hopelessness Scale (Beck et al. 1974), where respondents have to rate statements such as 'My future seems dark to me' and 'I might as well give up because I cannot make things better for myself'. Questions in the Beck Hopelessness Scale centre on feelings about the future, loss of motivation, and future expectations.

Positive expectations are captured using the single-item question 'What are your expectations for the year to come: will the next twelve months be better, worse or the same when it comes to your standard of living?'

With regard to subjective well-being, we discern three types of measures that were used in the included studies: the cognitive component of subjective well-being, the emotional component, or overall happiness.

Measures of the more cognitive component of subjective well-being include the Satisfaction with Life Scale (Diener et al. 1985), Student's Life Satisfaction Scale (Huebner 1991), Cantril Ladder (Cantril 1965), and single-item life satisfaction questions. Example questions from the Satisfaction with Life Scale include 'In most ways my life is close to ideal' and 'The conditions of my life are excellent'. Please note that several studies have by now found that single-item subjective well-being measures have acceptable reliability and validity (Schimmack and Oishi 2005; Abdel-Khalek 2006; Cheung and Lucas 2014).

The more emotional component of subjective well-being is usually captured using affect balance scales, such as the Positive Affect and Negative Affect Scale (PANAS; Watson et al. 1988), the Affect Balance Scale (ABS; Moriwaki 1974), and the Scale of Positive and Negative Experience (SPANE; Diener et al. 2010b). These scales can usually be subdivided into a positive affect scale and a negative affect scale. The positive affect scale of the PANAS, for example, asks respondents to indicate to what extent they felt excited or enthusiastic during the past few weeks, while the negative affect scale of the PANAS asks respondents to indicate to what extent they felt hostile or distressed during the past few weeks.

\footnotetext{
${ }^{3}$ Please note that the Herth Hope Index also includes more cognitive items and, hence, measures both components of hope. However, most emphasis of the Herth Hope Index is put on the emotional component of hope.
} 
Measures of overall happiness, capturing both the cognitive and emotional component of subjective well-being, include the Subjective Happiness Scale (Lyubomirsky and Lepper 1999) and a single-item overall happiness question.

\section{Presentation of Results}

In the literature review, we summarize the findings of these studies, examining the reported correlations between the different measures of hope and subjective well-being. When reporting coefficients, we consider a correlation between 0 and 0.19 to be very weak, between 0.2 and 0.39 to be weak, between 0.40 and 0.59 to be moderate, between 0.6 and 0.79 to be strong, and between 0.8 and 1 to be very strong (Evans 1996).

\section{Literature Review Findings}

When we turn to the existing empirical evidence, we observe that particularly in psychology, but increasingly also in sociology and economics, some empirical research has been conducted on the relationship between different types of hope and subjective well-being. However, there seems to be a division in research fields, within which specific measures of hope and subjective well-being are usually studied simultaneously. For example, there are only a few studies that compare affect and expectations, whereas the correlation between cognitive hope and life satisfaction is very well documented.

In an exploration of zero-order correlations, a number of patterns can be recognized. First, although there is generally a positive connection between cognitive hope and life satisfaction, it is apparent that the various aspects of Snyder's Hope scale are not connected with happiness in the same way. Agency, the belief that we are able to achieve our goals, has a stronger association with life satisfaction than the different pathways we can come up with to achieve our goals. It thus seems to be especially important for life satisfaction that we have the conviction that we can achieve our goals: this belief has a greater impact on life satisfaction than the process of getting there (Table 1).

Table 1 Relationships between hope and subjective well-being

\begin{tabular}{|c|c|c|c|c|c|}
\hline & \multicolumn{2}{|c|}{ Cognitive hope } & \multicolumn{2}{|c|}{ Emotional hope } & \multirow[t]{2}{*}{ Positive expectations } \\
\hline & Agency & Pathways & Hopefulness & Hopelessness & \\
\hline Life satisfaction & $\begin{array}{l}++ \\
++\end{array}$ & + & ++ & - & $+/ 0$ \\
\hline Affect balance & + & & +++ & - & $+/ 0$ \\
\hline Positive affect & ++ & & ++ & - & 0 \\
\hline Negative affect & $-/ 0$ & & - & ++ & - \\
\hline Overall happiness & ++ & & ++ & - & + \\
\hline
\end{tabular}

+ correlations are typically between 0.20 and $0.40 ;++$ correlations are typically between 0.40 and $0.60 ;+++$ correlations are typically greater than 0.60 ; - correlations are typically between -0.20 and -0.40 ; -correlations are typically between -0.40 and $-0.60 ;--$ correlations are typically less than -0.60 
Second, when comparing positive and negative affect, it is evident that they are not connected in the same way to cognitive hope. That is, the correlation between cognitive hope and positive feelings is generally stronger than the relationship between cognitive hope and negative feelings. From this difference, it can be concluded that a hopeful attitude is associated mainly with more positive feelings, while the absence of cognitive hope is not directly accompanied by strong negative feelings. For the other forms of hope, however, no differences between positive and negative feelings were found. These findings substantiate the idea that positive and negative affect are not merely opposites on one continuum but rather are distinct states of being that both relate to other constructs in dissimilar ways (Larsen and McGraw 2011).

Third, the relation between general positive expectations and happiness turns out to be weaker than the relationship between happiness and other forms of hope. While some studies have found a positive correlation, there appears to be no or even a negative relationship in other studies. This discrepancy may in part be due to the wide variety of questions about positive expectations since there is much less consistency in these types of questions. However, when looking at specific studies, positive expectations appear to be more weakly related to happiness than other forms of hope. This finding could be explained by the idea that there is a curvilinear relationship between expectations and subjective wellbeing (Arampatzi et al. 2019). Although previous studies have shown that positive expectations predict life satisfaction better than actual income (Frijters et al. 2012; Ekici and Koydemir 2016) and that moderately optimistic people can cope better with exogenous shocks (Arampatzi et al. 2019), these studies also warn about overly optimistic expectations, since subjective well-being seems to decrease if an outcome is worse than originally expected (Bell 1985; Schwartz \& Post 2002; Arampatzi et al. 2019). Compared to expectations, hope is less prone to resulting in disappointment and disillusionment, since it is inherently uncertain and requires personal effort. Therefore, having positive expectations might be a worse predictor of subjective well-being than hope, since the former can easily lead to disappointment, and the latter does not.

\section{Empirical Study}

The literature review thus highlighted three findings: (1) the association of subjective well-being with the agency component of cognitive hope is stronger than that with the pathways component, (2) the association of cognitive hope with positive affect is stronger than of cognitive hope with negative affect, and (3) expectations are only weakly correlated with all components of subjective well-being. At the same time, the reviewed studies are difficult to compare with each other, as the more emotional hope scales are disproportionately found in research on patients with a physical or psychological disorder, while the cognitive hope scales are disproportionately found in studies on the general population. Moreover, none of the included studies combined all types of subjective well-being and hope within one survey. Hence, we conducted an empirical study in which we further compared all the different types of hope and subjective well-being. 


\section{Data}

A two-wave panel dataset was collected in the US in 2016 and 2017 using Prolific, a virtual crowdsourcing platform similar to Amazon Mechanical Turk, where people can fill out surveys for small compensation (Sheehan 2017). Prolific has been used in many empirical studies in the social sciences, and previous studies have shown that online crowdsourcing in general, and Prolific in particular, offer high quality data (Buhrmester et al. 2011; Peer et al. 2017). Originally, 517 people participated in wave 1. Of this group, 338 also participated in wave 2 . Only these respondents were included in the analysis, and their characteristics are reported in Table 2, column 1. As shown in column 2, men are over-represented in the group of people who did not participate in wave 2, i.e. the 'dropouts'. However, in both the second and first wave, slightly more than half of the sample was male. The other characteristics of the drop-outs were not notably different from those of the research population. Since emotional hope was measured among only a subset of the first wave, only 167 of the respondents in the final analysis answered the questions on emotional hope in wave $1 .{ }^{4}$ Respondents reported their age, gender, household composition, income, and ethnicity. These characteristics were included as covariates.

\section{Measures}

The cognitive component of hope was measured using the ATHS (Snyder et al. 1991), where high scorers are regarded as more hopeful, more motivated to achieve their goals, and better able to think of ways to reach their goals. All eight items in the ATHS were scored on a scale from 1 (Definitely False) to 7 (Definitely True) and were averaged to calculate an overall score ranging from 1 to 7 . Apart from an overall cognitive hope measure, we constructed measures using the agency and pathways subscales. Emotional hope was estimated using the HHI (Herth 1992), where twelve statements were rated on a scale from 1 (Strongly Disagree) to 7 (Strongly Agree), and the average of statement scores was used as the total score. In addition, a single-item hopefulness measure was presented to respondents, asking: 'In the past 4 weeks, how often have you felt hopeful?' Possible answers ranged from 1 (Never) to 7 (Always). During the first wave, only a subsample of the entire sample filled out the HHI (167 out of 338). Positive expectations were measured using a single-item measure in which respondents had to answer the following questions: 'What are your expectations for the next twelve months: will the next twelve months be better, worse or the same, when it comes to your life in general?'. The possible answers were (1) Worse, (2) Same, and (3) Better.

With regard to the life satisfaction question, respondents had to provide an answer to a single question: 'All things considered, how satisfied are you with your life as a whole nowadays?' Possible answers ranged from 0 (very dissatisfied) to 10 (very satisfied). Positive affect and negative affect were measured using the PANAS scale, where respondents indicate to what extent they generally feel certain positive (alert, inspired, determined, attentive and active) and negative (upset, hostile, ashamed,

\footnotetext{
${ }^{4}$ Please note that respondents were selected to answer the Herth-questions at random, so the group that answered these questions does not differ from the group that did not.
} 
Table 2 Demographics of participants

Gender

- Male

- Female

Age

Household composition

- Single

- Single parent

- Two adults, no children

- Two adults, with children

- Other

Monthly household income

- Less than $\$ 900$

- $\$ 900$ - $\$ 1300$

- \$1300 - \$1800

- \$1800 - \$2700

- \$2700 - \$3200

- More than $\$ 3200$

Religion

-Important/very important

- Slightly important

- Not important/don't know

Ethnicity

- Caucasian/White

- African American

- Asian

- Other

Please note that these respondents were not included in this study

nervous and afraid) emotions on a scale from 1 (Never) to 7 (Always), resulting in an average score ranging from 1 to 7 . Finally, overall happiness was measured using the following single-item question: 'Taking all things together, how happy would you say you are?', where 0 means very unhappy, and 10 means very happy.

The internal reliability of all scales was sufficient (Cronbach's $\alpha>0.70$; Nunnally and Bernstein 1994) and well within the $\alpha$ ranges reported in different studies. The descriptive statistics for the hope and subjective well-being measures in both study waves - including the internal reliability scores for the utilized scales - can be found in Table 3.

\section{Correlations}

The bivariate correlations between the different types of hope and well-being show patterns that are largely in line with those found in the literature review (Table 4). 
Table 3 Descriptive statistics of hope and subjective well-being measures

\begin{tabular}{|c|c|c|c|}
\hline Wave $1(N=338)$ & Mean & Standard deviation & Cronbach's $\alpha$ \\
\hline Adult trait hope (1-7) & 4.91 & 1.07 & 0.90 \\
\hline Adult trait hope - agency (1-7) & 4.76 & 1.26 & 0.86 \\
\hline Adult trait hope - pathways $(1-7)$ & 5.06 & 1.05 & 0.83 \\
\hline $\begin{array}{l}\text { Herth hope index }(1-7) \\
(N=167)\end{array}$ & 4.99 & 1.09 & 0.90 \\
\hline Hopefulness (1-7) & 4.88 & 1.44 & $\mathrm{~N} / \mathrm{A}$ \\
\hline Positive expectations (1-3) & 1.85 & 0.69 & N/A \\
\hline Life satisfaction $(0-10)$ & 6.31 & 2.31 & N/A \\
\hline Positive affect (1-7) & 4.69 & 1.07 & 0.82 \\
\hline Negative affect (1-7) & 2.53 & 1.19 & 0.87 \\
\hline Overall happiness $(0-10)$ & 6.42 & 2.23 & N/A \\
\hline Wave $2(\mathrm{~N}=338)$ & Mean & Standard deviation & Cronbach's $\alpha$ \\
\hline Adult trait hope $(1-7)$ & 4.93 & 1.10 & 0.91 \\
\hline Adult trait hope - Agency (1-7) & 4.83 & 1.27 & 0.87 \\
\hline Adult trait hope - Pathways (1-7) & 5.05 & 1.10 & 0.85 \\
\hline Herth hope index $(N=167)(1-7)$ & 5.04 & 1.10 & 0.91 \\
\hline Hopefulness (1-7) & 4.70 & 1.38 & $\mathrm{~N} / \mathrm{A}$ \\
\hline Positive expectations (1-3) & 1.76 & 0.67 & $\mathrm{~N} / \mathrm{A}$ \\
\hline Life satisfaction $(0-10)$ & 6.26 & 2.22 & $\mathrm{~N} / \mathrm{A}$ \\
\hline Positive affect (1-7) & 4.79 & 1.03 & 0.80 \\
\hline Negative affect (1-7) & 2.62 & 1.15 & 0.86 \\
\hline Overall happiness $(0-10)$ & 6.36 & 2.24 & N/A \\
\hline
\end{tabular}

First, we find moderate to strong correlations of (1) cognitive and emotional hope measures with (2) overall happiness, life satisfaction, and positive affect measures. We also see that the associations of the subjective well-being measures with the agency component of hope are slightly stronger than with the pathways component of hope. Second, we find that the association of cognitive hope with positive affect is stronger than that with negative affect. In contrast to the literature review, we find only a weak correlation of negative affect with hopefulness and a moderate correlation with the HHI. Third, the correlations between positive expectations and the subjective well-being measures are generally weak. Finally, it is notable that the correlations in both studies are very similar. When we gauge the correlations of changes in hope with changes in subjective well-being between the two moments of measurement (Table 5), we see that these correlations are generally weaker than those between the level variables (Table 4). However, the earlier observed pattern of the relative strength of the relationships between the different hope and subjective well-being measures remains (Table 6).

\section{Nonlinearities}

The literature review and correlation analyses showed that cognitive and emotional hope have a relatively strong positive relation with well-being, while positive expectations appear 
Table 4 Bivariate correlations between hope and subjective well-being measures

\begin{tabular}{|c|c|c|c|c|c|c|}
\hline & \multicolumn{3}{|c|}{ Cognitive hope } & \multicolumn{2}{|l|}{ Emotional hope } & \multirow{2}{*}{$\begin{array}{l}\text { Positive } \\
\text { expectations }\end{array}$} \\
\hline & ATHS & $\begin{array}{l}\text { ATHS } \\
\text { (Agency) }\end{array}$ & $\begin{array}{l}\text { ATHS } \\
\text { (Pathways) }\end{array}$ & Herth Hope Index ${ }^{\#}$ & Hopefulness & \\
\hline \multicolumn{7}{|l|}{ Wave $1(\mathrm{~N}=338)$} \\
\hline Life satisfaction & $0.68^{*}$ & $0.72 *$ & $0.53 *$ & $0.59 *$ & $0.69 *$ & $0.39 *$ \\
\hline Positive affect & $0.66^{*}$ & $0.65^{*}$ & $0.56^{*}$ & $0.62 *$ & $0.57 *$ & $0.19 *$ \\
\hline Negative affect & $-0.42 *$ & $-0.40^{*}$ & $-0.38^{*}$ & $-0.41 *$ & $-0.30 *$ & -0.25 \\
\hline Overall happiness & $0.67 *$ & $0.70^{*}$ & $0.53 *$ & $0.58^{*}$ & $0.70^{*}$ & $0.38^{*}$ \\
\hline \multicolumn{7}{|l|}{ Wave $2(\mathrm{~N}=338)$} \\
\hline Life satisfaction & $0.69^{*}$ & $0.72 *$ & $0.56^{*}$ & $0.70 *$ & $0.72 *$ & $0.45 *$ \\
\hline Positive affect & $0.65^{*}$ & $0.65^{*}$ & $0.56^{*}$ & $0.61 *$ & $0.55^{*}$ & $0.33 *$ \\
\hline Negative affect & $-0.41^{*}$ & $-0.41 *$ & $-0.36^{*}$ & $-0.52 *$ & $-0.41 *$ & $-0.21 *$ \\
\hline Overall Happiness & $0.70^{*}$ & $0.70^{*}$ & $0.54 *$ & $0.75^{*}$ & $0.72 *$ & $0.46^{*}$ \\
\hline
\end{tabular}

${ }^{*} p<0.05 ; 0-0.19$ is regarded as a very weak correlation, $0.2-0.39$ as weak, $0.40-0.59$ as moderate, $0.6-0.79$ as strong and $0.8-1$ as very strong

\# $N=167$ for wave 1

to be only weakly related to well-being. One possible explanation for the latter finding is that the relation between expectations and well-being is non-linear; although moderate positive expectations are generally associated with greater well-being, this might not be the case when people expect too much from life and consequently become disappointed. Previous studies have indeed hinted that this might be the case (Bell 1985; Schwartz \& Post 2002; Arampatzi et al. 2019). To test this hypothesis, several fixed effects regressions were run, calculating the relation between differences in well-being and differences in hope between wave 1 and wave 2 for differing levels of hopefulness. ${ }^{5}$

To interpret these results more fully, Fig. 1 shows scatterplots for all the predicted values of happiness at the three levels of the different hope measures. Here, a non-linear line indicates that the well-being differences between low, moderate and high levels of hope are not equal.

The results show that, on average, lower levels of hope are associated with lower levels of well-being. However, it also appears that for several combinations of hope and happiness measures, the difference between moderate and high levels of hope makes a relatively small difference. This finding would indicate that for these measures, overly optimistic hopes do not generally translate into an equal rise in happiness and eventually may even result in a decline. This finding is quite clear for the relation of positive expectations with life satisfaction and positive affect; people with moderate and positive expectations hardly differ in their well-being scores. Moreover, the relation between the HHI and life satisfaction; the relation between the pathways subscale of the ATHS and affect and overall happiness; and of general hopefulness with negative affect and happiness also show indications of diminishing returns.

\footnotetext{
${ }^{5}$ Since positive expectations were measured as a categorical three-point variable, all other hope measures were also rescaled as such.
} 
Table 5 Bivariate correlations between hope and subjective well-being measures - changes between Wave 1 and Wave $2(N=338)$

\begin{tabular}{lcclllc}
\hline & $\Delta$ ATHS & $\begin{array}{l}\Delta \text { ATHS } \\
\text { (Agency) }\end{array}$ & $\begin{array}{l}\Delta \text { ATHS } \\
\text { (Pathways) }\end{array}$ & $\begin{array}{l}\Delta \text { Herth Hope } \\
\text { Index }\end{array}$ & $\begin{array}{l}\Delta \\
\text { Hopefulness }\end{array}$ & $\begin{array}{l}\Delta \text { Positive } \\
\text { expectations }\end{array}$ \\
\hline$\Delta$ Life Satisfaction & $0.52^{*}$ & $0.54^{*}$ & $0.38^{*}$ & $0.34^{*}$ & $0.48^{*}$ & 0.24 \\
$\Delta$ Positive Affect & $0.43^{*}$ & $0.44^{*}$ & $0.33^{*}$ & $0.32^{*}$ & $0.31^{*}$ & 0.14 \\
$\Delta$ Negative Affect & $-0.31^{*}$ & -0.35 & -0.21 & $-0.42^{*}$ & $-0.21^{*}$ & -0.13 \\
$\Delta$ Overall Happiness & $0.46^{*}$ & $0.50^{*}$ & $0.32^{*}$ & $0.41^{*}$ & $0.45^{*}$ & $0.25^{*}$ \\
\hline
\end{tabular}

$* p<0.05 ; 0-0.19$ is regarded as a very weak correlation, $0.2-0.39$ as weak, $0.40-0.59$ as moderate, $0.6-0.79$ as strong and $0.8-1$ as very strong

\# $N=167$

\section{Discussion and Conclusion}

Over the past decades, the relation between hope and well-being has become a topic of increasing interest in several academic disciplines, such as psychology, economics, sociology, and political science. How people perceive the future appears to greatly influence how they behave and experience their current situation, and research on the topic can thus lead to new insights into the drivers of well-being. However, different disciplines define and operationalize hope and

Table 6 Fixed effects regression on the relation between hope and subjective well-being $(N=338)$

\begin{tabular}{|c|c|c|c|c|}
\hline & Life satisfaction & Positive affect & Negative affect & Happiness \\
\hline \multicolumn{5}{|l|}{ ATHS } \\
\hline Middle & $1.31 * * *(0.23)$ & $0.27 * * *(0.10)$ & $-0.46 * * *(0.11)$ & $1.16^{* * *}(0.24)$ \\
\hline High & $2.01 * * *(0.28)$ & $0.71 * * *(0.12)$ & $-0.65 * * *(0.14)$ & $1.93 * * *(0.29)$ \\
\hline \multicolumn{5}{|l|}{ ATHS (Agency) } \\
\hline Middle & $1.35 * * *(0.21)$ & $0.30 * * *(0.09)$ & $-0.60 * * *(0.10)$ & $1.22 * * *(0.22)$ \\
\hline High & $1.94 * * *(0.27)$ & $0.72 * * *(0.12)$ & $-0.77 * * *(0.13)$ & $2.02 * * *(0.27)$ \\
\hline \multicolumn{5}{|l|}{ ATHS (Pathways) } \\
\hline Middle & $0.97 * * *(0.21)$ & $0.43 * * *(0.09)$ & $-0.32 * * *(0.10)$ & $1.08 * * *(0.21)$ \\
\hline High & $1.39 * * *(0.26)$ & $0.57 * * *(0.11)$ & $-0.38 * * *(0.12)$ & $1.32 * * *(0.26)$ \\
\hline \multicolumn{5}{|c|}{ Herth hope index $(\mathrm{N}=167)$} \\
\hline Middle & $1.10 * * *(0.36)$ & $0.24 *(0.15)$ & $-0.69 * * *(0.15)$ & $1.23 * * *(0.34)$ \\
\hline High & $1.36 * * *(0.44)$ & $0.63 * * *(0.19)$ & $-0.98 * * *(0.19)$ & $1.74 * * *(0.42)$ \\
\hline \multicolumn{5}{|l|}{ Hopefulness } \\
\hline Middle & $1.08 * * *(0.18)$ & $0.23 * * *(0.08)$ & $-0.25 * * *(0.09)$ & $1.13 * * *(0.18)$ \\
\hline High & $1.61 * * *(0.22)$ & $0.45 * * *(0.10)$ & $-0.27 * *(0.11)$ & $1.47 * * *(0.23)$ \\
\hline \multicolumn{5}{|c|}{ Positive Expectations } \\
\hline Staying the same & $1.14 * * *(0.24)$ & $0.29 * * *(0.11)$ & $-0.19 *(0.12)$ & $0.91 * * *(0.25)$ \\
\hline Getting better & $1.33 * * *(0.27)$ & $0.36 * * *(0.12)$ & $-0.29 * *(0.13)$ & $1.29 * * *(0.27)$ \\
\hline
\end{tabular}

$* p<0.10, * * p<0.05, * * * p<0.01$ 


\begin{tabular}{|c|c|c|c|c|}
\hline & Life satisfaction & Positive affect & Negative affect & Happiness \\
\hline ATHS & & & & \\
\hline $\begin{array}{l}\text { ATHS } \\
\text { (Agency) }\end{array}$ & & & & \\
\hline $\begin{array}{l}\text { ATHS } \\
\text { (Pathways) }\end{array}$ & & & & \\
\hline $\begin{array}{l}\text { Herth Hope } \\
\text { Index }\end{array}$ & & & & \\
\hline Hopefulness & & & & \\
\hline $\begin{array}{l}\text { Positive } \\
\text { Expectations }\end{array}$ & & & & \\
\hline
\end{tabular}

Fig. 1 Scatterplots for predicted values of happiness at three different levels of hope

well-being in diverging ways. Hence, it is difficult to relate findings from one field of research to those from another. In this study, we combined a literature review and an empirical investigation of the relation between different types of hope and subjective well-being. As such, this study provides insight and nuance to the differing relations between these two concepts. Although hope and subjective well-being generally seem to be correlated, the strength of the relations differ between the types of hope and subjective well-being. Most notably, expectations appear to be only weakly related to subjective well-being. Our data suggest that this relation could be non-linear, as overly optimistic expectations may harm subjective well-being through disappointment.

By combining a literature review and empirical study, this research offers a structured and comprehensive overview of how hope and subjective well-being are related. However, to maintain comparability, some important findings could not be included in the current article. First, the literature review focuses solely on crosssectional data and zero-order correlations, overlooking studies conducted with regression analyses or panel data, which are more common in the field of economics and in more recent studies within psychology. Moreover, only a handful of the instruments used to measure happiness and hope could be included in the empirical study, disregarding, for example, popular measures such as the Satisfaction With Life Scale and the Miller Hope Scale. Nonetheless, the current research is unique in comparing a wide range of findings and instruments from different disciplines. The aim of this study was not to be exhaustive but to offer a comprehensive first step to greater comparability across disciplines. Future research could extend these findings by including even more measures. Moreover, making use of larger datasets 
enables a more detailed study of how the subjective well-being of different groups of people is affected by their hopes for a positive future.

In summary, our research shows that although greater hopes usually go hand-in-hand with higher subjective well-being levels, we should be mindful of the nuances of this relation. First, the relationship between hope and subjective well-being is contingent on the definitions used, and not all types of hope and well-being are equally strongly related. Second, more optimistic hopes are not always associated with higher levels of subjective well-being. Especially with regard to positive expectations, it might pay off to remain moderately cautious. Third, cognitive and emotional hope, measured with the ATHS and Herth Hope Index, do appear to have strong and robust positive relations with all components of subjective well-being in this study. More generally, this research provides insight into how findings on hope and subjective well-being from different disciplines can be compared. Our findings have methodological implications, since they help to interpret the relations between specific measures of hope and subjective well-being. Moreover, they have important policy-implications. The strong relation between hope and subjective well-being indicates that policies affecting hope, either in a positive or negative way, will also influence well-being. Increased insecurities, affecting people's perspective of the future, for example because of temporary employment-contracts, increasing debts, or weakening social safety nets, will therefore inevitably also affect people's subjective well-being. Furthermore, it means that interventions aimed at increasing hope can be used to simultaneously increase subjective well-being, but also that policies aiming to raise either hope or subjective wellbeing without taking into account the relation between the two may not be as effective. The findings of this study could help to better understand the mechanisms underlying increased well-being, and could be applied to for example public policy, education and health care.

A limitation of this study is that it used only two waves of data and a relatively small sample. Therefore, we should be very cautious about making any causal inferences. Future research could test the relations between different types of hope and well-being in a larger sample, comprising more waves. Additionally, experimental set-ups would be needed to study the causal relation between changing levels of hope and well-being. Moreover, although we found indications that the relation between expectations and some measures of hope and well-being is non-linear, more research is needed to examine the level at which increased hope no longer improves well-being and to verify which components of a hopeful disposition lead to diminishing returns in terms of wellbeing.

\section{Compliance with Ethical Standards}

Conflict of Interest Martijn Burger and Emma Pleeging received financial support from the Goldschmeding Foundation for People, Work and Economy (project 'Hope as an Incentive'). Job van Exel declares that he has no conflict of interest.

\section{Appendix: Studies Included in Literature Review}

Please anchor Table 7 here. 
Table 7 Detailed analysis of existing studies on hope and happiness

\begin{tabular}{|c|c|c|c|c|c|}
\hline & \multirow{2}{*}{\multicolumn{2}{|c|}{$\begin{array}{l}\text { Cognitive hope } \\
\text { (Snyder's adult } \\
\text { trait hope scale; } \\
\text { Variations on } \\
\text { Snyder's hope } \\
\text { scale) }\end{array}$}} & \multicolumn{2}{|c|}{ Emotional hope } & \multirow{3}{*}{$\begin{array}{l}\text { Positive expectations } \\
\text { (Trust in own future; } \\
\text { Positive expectations } \\
\text { about own future).; }\end{array}$} \\
\hline & & & $\begin{array}{l}\text { (Herth hope ir } \\
\text { hope scale; B } \\
\text { hopelessness }\end{array}$ & $\begin{array}{l}\text { ndex; Miller } \\
\text { eck } \\
\text { scale) }\end{array}$ & \\
\hline & Agency & Pathways & Hopefullness & Hopelessness & \\
\hline $\begin{array}{l}\text { Life satisfaction (Satisfaction with } \\
\text { life scale students life } \\
\text { satisfaction scale single item } \\
\text { life satisfaction questions) }\end{array}$ & $\begin{array}{l}++^{1} \\
++^{2} \\
++^{3} \\
++^{4} \\
+^{5} \\
+++^{6} \\
+++^{7} \\
++^{34} \\
++^{35} \\
++^{36} \\
++^{37} \\
++^{38} \\
++^{39}\end{array}$ & $\begin{array}{l}+^{8} \\
+{ }^{9} \\
+{ }^{10} \\
++^{11} \\
++^{12} \\
++^{13} \\
++^{14}\end{array}$ & $\begin{array}{l}++^{15} \\
++^{16} \\
++^{17} \\
++++^{18} \\
++^{19} \\
++^{20}\end{array}$ & $\begin{array}{l}0^{21} \\
--22 \\
--23 \\
--24 \\
---25\end{array}$ & $\begin{array}{l}++^{26} \\
0^{27} \\
+^{28} \\
+^{29} \\
0^{30} \\
0^{31} \\
+^{33}\end{array}$ \\
\hline Affect Balance Score & +40 & & $+++^{41}$ & $\begin{array}{l}---42 \\
--43 \\
--44\end{array}$ & $\begin{array}{l}+++^{45} \\
0^{46} \\
0^{47} \\
+^{48} \\
0^{49} \\
+^{50}\end{array}$ \\
\hline Positive affect & $\begin{array}{l}+^{51} \\
+^{60} \\
+++^{61} \\
+^{62} \\
++^{63}\end{array}$ & $\begin{array}{l}+^{52} \\
+^{53}\end{array}$ & $\begin{array}{l}+++^{54} \\
++^{55}\end{array}$ & $\begin{array}{l}--56 \\
-57 \\
--58\end{array}$ & $0^{59}$ \\
\hline Negative affect & $\begin{array}{l}0^{64} \\
-71 \\
-72 \\
-73 \\
-74 \\
0^{75} \\
0^{76}\end{array}$ & $\begin{array}{l}-65 \\
0^{66}\end{array}$ & ---67 & $\begin{array}{l}+{ }^{68} \\
++{ }^{69}\end{array}$ & -70 \\
\hline $\begin{array}{l}\text { Overall happiness (Subjective } \\
\text { happiness scale; Single item } \\
\text { overall happiness questions) }\end{array}$ & $\begin{array}{l}++^{77} \\
+{ }^{78}\end{array}$ & & $\begin{array}{l}++^{80} \\
+{ }^{81}\end{array}$ & -82 & $\begin{array}{l}+++^{83} \\
0^{84}\end{array}$ \\
\hline
\end{tabular}


Table 7 (continued)

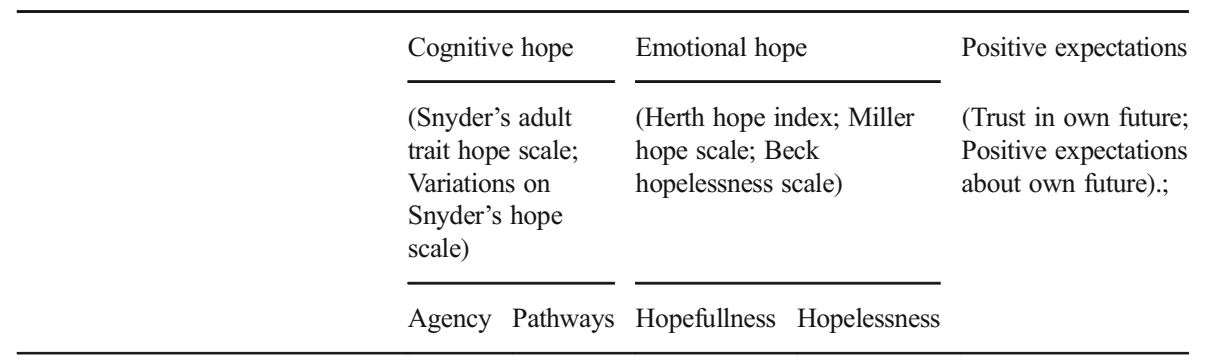

$+++79$

$-=-0.40--0.20 ;--=-0.60--0.40 ;--=<-0.60 ;+=0.20-0.40 ;++=0.40-0.60 ;+++>0.60 ; 0=-0.20-$ 0.20

${ }^{1}$ Bailey et al. (2007). SWLS versus ATHS agency subscale. $\mathrm{R}=0.58, p<0.01$. Population: US (students)

${ }^{2}$ Chang (2003). SWLS versus ATHS agency subscale. $\mathrm{R}=0.54, p<0.01$. Population USA (middle aged males)

${ }^{3}$ Chang (2003). SWLS versus ATHS agency subscale. $\mathrm{R}=0.41, p<0.001$. Population USA (middle aged females)

${ }^{4}$ Cotton Bronk et al. (2009). SWLS versus ATHS agency subscale. $R=0.58, p<0.01$

${ }^{5}$ Bailey et al. (2007). QOLI (Quality of Life Inventory) versus ATHS agency subscale. R=0.37, p $<0.001$. Population: US (students)

${ }^{6}$ Smedema et al. (2014). SWLS versus ATHS agency subscale. $R=0.678, p<0.01$. Population: Adults with spinal cord injuries

${ }^{7}$ Kwon and Hugelshofer (2010). SWLS versus ATHS agency subscale. R=062 $\mathrm{p}<0.01$. Population: LGB adults in China

${ }^{8}$ Bailey et al. (2007). SWLS versus ATHS pathways subscale. $\mathrm{R}=0.34, \mathrm{p}<0.01$. Population: US (students)

${ }^{9}$ Chang (2003). SWLS versus ATHS pathways subscale. $\mathrm{R}=0.32, \mathrm{p}<0.01$. USA (middle aged males)

${ }^{10}$ Chang (2003). SWLS versus ATHS pathways subscale. $R=0.20, p<0.01$. USA (middle aged females)

${ }^{11}$ Cotton Bronk et al. (2009). SWLS versus ATHS pathways subscale. $R=0.36, p<0.01$

${ }^{12}$ Bailey et al. (2007). QOLI (Quality of Life Inventory) versus ATHS pathways subscale. $R=0.25, \mathrm{p}<0.001$. Population: US (students)

${ }^{13}$ Smedema et al. (2014). SWLS versus ATHS pathways subscale. $\mathrm{R}=0.506, p<0.01$. Population: Adults with spinal cord injuries

${ }^{14}$ Kwon and Hugelshofer (2010). SWLS versus ATHS pathways subscale. $R=0.56 \mathrm{p}<0.01$. Population: LGB adults in China

${ }^{15}$ Rustoen et al. (2010). Life satisfaction versus HHI. $\mathrm{R}=0.547, P<0.01$. Population: Cancer patients

${ }^{16}$ Wnuk et al. (2012). Life satisfaction versus HHI. $\mathrm{R}=0.46, \mathrm{P}<0.01$. Population: Poland (cancer patients)

${ }^{17}$ Gestel-Timmermans et al. (2010). MANSA (life and domain satisfaction) versus HHI. R =0.56, $P<0.05$. Population: Netherlands (patients with serious mental health problems)

${ }^{18}$ Landeen et al. (2000). Cantrill ladder versus Miller Hope Scale. $\mathrm{R}=0.68$. No significance level reported. Population: Canada (patients with schizophrenia)

${ }^{19}$ Bunston et al. (1996) (In: Kalitzikus \& Twohig eds., Bordering Biomedicine). Global quality of life versus Herth Hope Index. $\mathrm{R}=0.47, \mathrm{P}<0.01$. (Cancer patients)

${ }^{20}$ Coward (1996). Cognitive wellbeing versus HHI. $\mathrm{R}=0.53, \mathrm{P}<0.01$. Population: US

${ }^{21}$ Costa and McCrae (1980). Life satisfaction versus Hopelessness scale. $\mathrm{R}=-0.18, p<0.05$. Population: United States (35-85 aged white males (largely veterans)

22 Shek (1993). Life satisfaction versus hopelessness scale. $\mathrm{R}=-0.51, \mathrm{P}<0.01$. Population: China (students) 
${ }^{23}$ Chioqueta and Stiles (2007). Life satisfaction versus hopelessness scale. $\mathrm{R}=-0.57, \mathrm{P}<0.01$. Population: Norway (students)

${ }^{24}$ Lucas et al. (1996). SWLS versus hopelessness scale. $\mathrm{R}=-0.49, P<0.01$. Population: US (students)

${ }^{25}$ Lucas et al. (1996). Life satisfaction versus hopelessness scale. $\mathrm{R}=-0.60, \mathrm{P}<0.01$. Population: US (students)

${ }^{26}$ Cheung (2016). Life satisfaction versus single item (“To what degree are you confident about your future?”). $\mathrm{R}=0.43, p<0.01$

${ }^{27}$ Arampatzi et al. (2019). Life satisfaction (single item) versus positive expectations index. $\mathrm{R}=0.14$,. Population: Greece

${ }^{28}$ Mähönen et al. (2012). Global wellbeing scale versus social expectations. $\mathrm{R}=0.21, P<0.05$. Population: Russian immigrants in Finland

${ }^{29}$ Mähönen et al. (2012). Global wellbeing scale $\mathrm{X}$ years later versus social expectations. $\mathrm{R}=0.26, \mathrm{P}<0.01$. Population: Russian immigrants in Finland

${ }^{30}$ Mähönen et al. (2012). Global wellbeing scale versus economic expectations. $\mathrm{R}=0.10, P>0.05$. Population: Russian immigrants in Finland

${ }^{31}$ Mähönen et al. (2012). Global wellbeing scale $\mathrm{X}$ years later versus economic expectations. $\mathrm{R}=0.12$, $P>0.05$. Population: Russian immigrants in Finland

32 Emmons (1986). SWLS versus single item ("In the future, how likely is it that you will be successful in achieving [personal goal]?"). $\mathrm{R}=0.26, \mathrm{P}<0.05$

${ }^{33}$ Yalçin and Malkoç (2015). SWLS versus ATHS. R=0.43 $p<0.01$. Population: Turkey (students)

${ }^{34}$ Bailey and Snyder (2007). SWLS versus ATHS. R=0.51, $\mathrm{p}<0.01$. Population: US (students)

${ }^{35}$ Marques et al. (2013). Student's Life Satisfaction Scale versus CHS. $R=0.55, p<0.01$. Population: Portugal (adolescents)

${ }^{36}$ Aghababaei et al. (2016). SWLS versus ATHS. R =0.49, $\mathrm{p}<0.01$. Population: Iran (students)

${ }^{37}$ Halama (2010). SWLS versus ATHS. $R=0.381, p<0.01$

${ }^{38}$ Hutz et al. (2014). SWLS versus ATHS. $R=0.41$ (no significance score). Population: Brazilian population

${ }^{39}$ Hutz et al. (2014). SWLS versus ATHS. $R=0.54$ (no significance score). Population: US population

${ }^{40} \mathrm{Ziv}$ et al. (2011). PANAS affect balance versus ATHS. $\mathrm{R}=0.28, p<0.05$

${ }^{41}$ Coward (1996). ABS versus HHI. $\mathrm{R}=0.64, P<0.01$. Population: US

${ }^{42}$ Costa and McCrae (1980). ABS versus Hopelessness scale. $\mathrm{R}=-0.61, \mathrm{p}<0.01$

${ }^{43}$ Sisask et al. (2009). WHO-5 versus Hopelessness scale. $\mathrm{R}=-0.412, P<0.05$. Population: Norway (suicide attempters)

${ }^{44}$ Sisask et al. (2009). WHO-5 versus Hopelessness scale, single item. $\mathrm{R}=-0.332, \mathrm{P}<0.05$. Population: Norway (suicide attempters)

${ }^{45}$ Kamman and Flett (1983). ABS (Affect Balance Score) vs single item ("My future looks good). R= +.61 $p<0.01$. Population: New Zealand (18+)

${ }^{46}$ Mähönen et al. (2012). Mood versus social expectations. $\mathrm{R}=0.14, P>0.05$. Population: Russian immigrants in Finland

${ }^{47}$ Mähönen et al. (2012). Mood versus economic expectations. $\mathrm{R}=0.04, \mathrm{P}>0.05$. Population: Russian immigrants in Finland

${ }^{48}$ Mähönen et al. (2012). Mood 1 year later versus social expectations. $\mathrm{R}=0.21, \mathrm{P}<0.05$. Population: Russian immigrants in Finland

${ }^{49}$ Mähönen et al. (2012). Mood 1 year later versus economic expectations. $\mathrm{R}=0.04, \mathrm{P}>0.05$. Population: Russian immigrants in Finland

${ }^{50}$ Emmons (1986). Affect Balance Scale versus single item ("In the future, how likely is it that you will be successful in achieving [personal goal]?"). $\mathrm{R}=0.31, \mathrm{P}<0.01$

${ }^{51} \mathrm{Lu}$ and $\mathrm{Hsu}$ (2013). PANAS positive affect versus ATHS agency subscale. $\mathrm{R}=0.29, p<0.05$. Population: student athletes in Taiwan

${ }^{52} \mathrm{Ziv}$ et al. (2011). PANAS positive affect versus ATHS pathways subscale. $\mathrm{R}=0.31, \mathrm{p}<0.05$ 
${ }^{53} \mathrm{Lu}$ and Hsu (2013). PANAS positive affect versus ATHS pathways subscale. $\mathrm{R}=0.34, \mathrm{p}<0.05$. Population: student athletes in Taiwan

${ }^{54}$ Wnuk et al. (2012). Feeling loved versus HHI. $\mathrm{R}=0.87, \mathrm{R}<0.01$. Population: Poland (cancer patients)

${ }^{55}$ Bunston et al. (1996) (In: Kalitzikus \& Twohig eds., Bordering Biomedicine). ABS positive affect versus Herth Hope Index. $\mathrm{R}=0.52, P<0.01$. (Cancer patients)

${ }^{56}$ Velting (1999). Positive emotions from the big five personality scale NEO Personality Inventory versus hopelessness scale. $\mathrm{R}=-0.49, \mathrm{P}<0.01$. Population: US (Students)

${ }^{57}$ Lucas et al. (1996). PANAS positive affect versus hopelessness scale. $\mathrm{R}=-0.27, \mathrm{P}<0.01$. Population: US (students)

${ }^{58}$ Lucas et al. (1996). ABS positive affect versus hopelessness scale. $\mathrm{R}=-0.55, \mathrm{P}<0.01$. Population: US (Students)

${ }^{59}$ Emmons (1986). Positive affect versus single item ("In the future, how likely is it that you will be successful in achieving [personal goal]?"). $\mathrm{R}=0.13, \mathrm{P}>0.05$

${ }^{60}$ Yalçin and Malkoç (2015). SPANE positive affect versus ATHS. R $=0.39 p<0.01$. Population: Turkey (students)

${ }^{61}$ Gallagher and Lopez (2009). PANAS positive affect versus RSHS. $\mathrm{R}=0.62 p<0.05$. Population: US (students)

${ }^{62}$ Hutz et al. (2014). PANAS positive affect versus ATHS. $\mathrm{R}=0.39$ (no significance score). Population: Brazilian population

${ }^{63}$ Hutz et al. (2014). PANAS positive affect versus ATHS. $\mathrm{R}=0.43$ (no significance score). Population: US population

${ }^{64} \mathrm{Lu}$ and Hsu (2013). PANAS negative affect versus ATHS agency subscale. $\mathrm{R}=0.01$ N.S. Population: student athletes in Taiwan

${ }^{65} \mathrm{Ziv}$ et al. (2011). PANAS negative affect versus ATHS pathways subscale. $\mathrm{R}=-0.28, \mathrm{p}<0.05$

${ }^{66} \mathrm{Lu}$ and $\mathrm{Hsu}$ (2013). PANAS negative affect versus ATHS pathways subscale. $\mathrm{R}=-0.12$ N.S. Population: student athletes in Taiwan

${ }^{67}$ Wnuk et al. (2012). Feeling lonely versus HHI. $\mathrm{R}=-0.65, \mathrm{R}<0.01$. Population: Poland (cancer patients)

${ }^{68}$ Lucas et al. (1996). PANAS negative affect versus hopelessness scale. $\mathrm{R}=0.40, P<0.01$. Population: US (Students)

${ }^{69}$ Lucas et al. (1996). PANAS negative affect versus hopelessness scale. $\mathrm{R}=0.55, \mathrm{P}<0.01$. Population: US (students)

${ }^{70}$ Emmons (1986). Negative affect versus single item ("In the future, how likely is it that you will be successful in achieving [personal goal]?"). $\mathrm{R}=-0.34, \mathrm{P}<0.01$

${ }^{71}$ Yalçin and Malkoç (2015). SPANE negative affect versus ATHS. R $=-0.32 p<0.01$. Population: Turkey (students)

${ }^{72}$ Gallagher and Lopez (2009). PANAS negative affect versus RSHS. $\mathrm{R}=-0.38 \mathrm{p}<0.05$. Population: US (students)

${ }^{73}$ Yalçin and Malkoç (2015). SPANE negative affect versus ASHS. $R=-0.34 \mathrm{p}<0.01$. Population: Turkey (students)

${ }^{74}$ Hutz et al. (2014). PANAS negative affect versus ATHS. R = -0.34 (no significance score). Population: Brazilian population

${ }^{75}$ Hutz et al. (2014). PANAS negative affect versus ATHS. $\mathrm{R}=-0.11$ (no significance score). Population: US population

76 Ong et al. (2006). PANAS negative affect versus ATHS. R $=-0.15$ N.S. Population: US population

${ }^{77}$ Gallagher and Lopez (2009). SHS versus RSHS. R $=0.50, \mathrm{p}<0.05$. Population: US (students)

${ }^{78}$ Aghababaei et al. (2016). SHS versus ATHS. $\mathrm{R}=0.38, \mathrm{p}<0.01$. Population: Iran (students)

${ }^{79}$ Abdel-Khalek (2006). Happiness versus ATHS. $\mathrm{R}=0.68, \mathrm{p}<0.01$. Population: Kuwait (students)

${ }^{80} \mathrm{Wnuk}$ et al. (2012). Happiness in recent days versus HHI. $\mathrm{R}=0.42, \mathrm{P}<0.01$. Population: Poland (cancer patients) 
${ }^{81}$ Phillips-Salimi et al. (2007). Index of wellbeing versus Herth Hope Index. $R=0.33 \mathrm{p}<0.01$. Population: US adolescents and young adults with cancer

82 Satici and Uysal (2016). Subjective happiness versus Hopelessness scale. $\mathrm{R}=-0.38, \mathrm{P}<0.01$. Population: Turkey (students)

${ }^{83}$ Kamman and Flett (1983). Happiness vs single item ("My future looks good) $\mathrm{R}=0.64 \mathrm{p}<0.01$. Population: New Zealand (18+)

${ }^{84}$ Arampatzi et al. (2019). Happiness (single item) versus positive expectations index. $\mathrm{R}=0.12$,. Population: Greece

Open Access This article is licensed under a Creative Commons Attribution 4.0 International License, which permits use, sharing, adaptation, distribution and reproduction in any medium or format, as long as you give appropriate credit to the original author(s) and the source, provide a link to the Creative Commons licence, and indicate if changes were made. The images or other third party material in this article are included in the article's Creative Commons licence, unless indicated otherwise in a credit line to the material. If material is not included in the article's Creative Commons licence and your intended use is not permitted by statutory regulation or exceeds the permitted use, you will need to obtain permission directly from the copyright holder. To view a copy of this licence, visit http://creativecommons.org/licenses/by/4.0/.

\section{References}

Abdel-Khalek. (2006). Measuring happiness with a single-item scale. Social Behavior and Personality, 34(2), $139-150$

Aghababaei, N., Sohrabi, F., Eskandari, H., Borjali, A., Farrokhi, N., \& Chen, Z. J. (2016). Predicting wellbeing by religious and scientific attitudes with hope, purpose in life, and death anxiety as mediators. Personality and Individual Differences, 90.

Alarcon, G. M., Bowling, N. A., \& Khazon, S. (2013). Great expectations: A meta-analytic examination of optimism and hope. Personality and Individual Differences, 54(7), 821-827.

Arampatzi, E., Burger, M., Stavropoulos, S., \& Tay, L. (2019). The role of positive expectations for resilience to adverse events: Subjective well-being before, during and after the Greek bailout referendum. Journal of Happiness Studies, 1-31.

Avey, J. B., Reichard, R. J., Luthans, F., \& Mhatre, K. H. (2011). Meta-analysis of the impact of positive psychological capital on employee attitudes, behaviors, and performance. Human Resource Development Quarterly, 22(2), 127-152.

Bailey, T. C., \& Snyder, C. R. (2007). Satisfaction with life and hope: A look at age and marital status. The Psychological Record, 57(2), 233-240.

Bailey, T. C., Eng, W., Frishch, M. B., \& Snyder, C. R. (2007). Hope and optimism as related to life satisfaction. The Journal of Positive Psychology, 2(3), 168-175.

Bar-Tal, D. (2001). Why does fear override hope in societies engulfed by intractable conflict, as it does in the Israeli society? Political Psychology, 22(3), 601-627.

Beck, A. T., Weissman, A., Lester, D., \& Trexler, L. (1974). The measurement of pessimism: The hopelessness scale. Journal of Consulting and Clinical Psychology, 42(6), 861.

Bell, D. E. (1985). Disappointment in decision making under uncertainty. Operations Research, 33(1), 1-27.

Boukala, S., \& Dimitrakopoulou, D. (2016). The politics of fear versus the politics of Hope: Analysing the 2015 Greek election and referendum campaigns. Critical Discourse Studies, 14(1), 39-55.

Buhrmester, M., Kwang, T., \& Gosling, S. D. (2011). Amazon's mechanical Turk. A new source of inexpensive, yet high-quality, data? Perspectives on Psychological Science, 6(1), 3-5.

Bunston, T., Mings, D., Mackie, A., \& Jones, D. (1996). Facilitating hopefulness: The determinants of hope. Journal of Psychosocial Oncology, 13(4), 79-103.

Cantril, H. (1965). The pattern of human concern. New Brunswick, NJ: Rutger University Press.

Chang, E. C. (2003). A critical appraisal and extension of hope theory in middle-aged men and women: Is it important to distinguish agency and pathways components. Journal of Social and Clinical Psychology, 22(2), 121-143.

Cheung, F. (2016). Can income inequality be associated with positive outcomes? Hope mediates the positive inequality-happiness link in rural China. Social Psychological and Personality Science, 7(4), 320-330. 
Cheung, F., \& Lucas, R. E. (2014). Assessing the validity of single-item life satisfaction measures: Results from three large samples. Quality of Life Research, 23(10), 2809-2818.

Chioqueta, A. P., \& Stiles, T. C. (2007). The relationship between psychological buffers, hopelessness, and suicidal ideation. Identification of Protective Factors. Crisis, 28(2), 67-73.

Cohen-Chen, S., Halperin, E., Crisp, R. J., \& Gross, J. J. (2013). Hope in the Middle East: Malleability beliefs, Hope, and the willingness to compromise for peace. Social Psychological and Personality Science, 5(1), $67-75$.

Costa, P. T., \& McCrae, R. R. (1980). Influence of extraversion and neuroticism on subjective well-being: Happy and unhappy people. Journal of Personality and Social Psychology, 38(4), 668-678.

Cotton Bronk, K., Hill, P. L., Lapsley, D. K., Talib, T. L., \& Finch, H. (2009). Purpose, hope, and life satisfaction in three age groups. The Journal of Positive Psychology, 4(6), 500-510.

Coward, D. D. (1996). Self-transcendence and correlates in healthy populations. Nursing Research, 45(2), 116-121.

Curry, L. A., Snyder, C. R., Cook, D. L., Ruby, B. C., \& Rehm, M. (1997). Role of hope in academic and sport achievement. Journal of Personality and Social Psychology, 73(6), 1257-1267.

Diener, E. D., Emmons, R. A., Larsen, R. J., \& Griffin, S. (1985). The satisfaction with life scale. Journal of Personality Assessment, 49(1), 71-75.

Diener, E., Suh, E. M., Lucas, R. E., \& Smith, H. L. (1999). Subjective well-being: Three decades of progress. Psychological Bulletin, 125(2), 276-302.

Diener, E. D., Ng, W., Harter, J., \& Arora, R. (2010a). Wealth and happiness across the world: Material prosperity predicts life evaluation, whereas psychosocial prosperity predicts positive feeling. Journal of Personality and Social Psychology, 99(1), 52-61.

Diener, E., Wirtz, D., Tov, W., Kim-Prieto, C., Choi, D. W., Oishi, S., \& Biswas-Diener, R. (2010b). New well-being measures: Short scales to assess flourishing and positive and negative feelings. Social Indicators Research, 97(2), 143-156.

Drahos, P. (2004). Trading in public Hope. The Annals of the American Academy of Political and Social Science, 592, 18-38.

Emmons, R. A. (1986). Personal strivings: An approach to personality and subjective well-being. Journal of Personality and Social Psychology, 51(5), 1058-1068.

Evans, J. D. (1996). Straightforward statistics for the behavioral sciences. Pacific Grove: Brooks/Cole Publishing.

Foster, G., \& Frijters, P. (2014). The formation of expectation: Competing theories and new evidence. Journal of Behavioral and Experimental Economics, 53, 66-81.

Foster, G., Frijters, P., \& Johnston, D. W. (2012). The triumph of Hope over disappointment: A note on the utility value of good health expectations. Journal of Economic Psychology, 33(1), 206-214.

Frijters, P., Liu, A. Y. C., \& Meng, X. (2012). Are optimistic expectations keeping the Chinese happy? Journal of Economic Behavior \& Organization, 81(1), 159-171.

Gallagher, M. W., \& Lopez, S. J. (2009). Positive expectancies and mental health: Identifying the unique contributions of hope and optimism. The Journal of Positive Psychology, 4(6), 548-556.

Gestel-Timmermans, H., van den Boogaard, J., Brouwers, E., Herth, K., \& van Nieuwenhuizen, C. (2010). Hope as a determinant of mental health recovery: A psychometric evaluation of the Herth Hope indexDutch version. Scandinavian Journal of Caring Sciences, 24(s1), 67-74.

Greenaway, K. H., Cichocka, A., van Veelen, R., Likki, T., \& Branscombe, N. R. (2016). Feeling hopeful inspires support for social change. Political Psychology, 37(1), 89-107.

Halama, P. (2010). Hope as a mediator between personality traits and life satisfaction. Studia Psychologica, 52(4), 309-314.

Herth, K. (1992). Abbreviated instrument to measure hope: Development and psychometric evaluation. Journal of Advanced Nursing, 17(10), 1251-1259.

Huebner, E. S. (1991). Initial development of the student's life satisfaction scale. School Psychology International, 12(3), 231-240.

Hutz, C. S., Midgett, A., Pacico, J. C., Bastianello, M. R., \& Zanon, C. (2014). The relationship of Hope, optimism, self-esteem, subjective well-being, and personality in Brazilians and Americans. Psychology, 5(6), 514-522.

Jarymowicz, M., \& Bar-Tal, D. (2006). The dominance of fear over hope in the life of individuals and collectives. European Journal of Social Psychology, 36(3), 367-392.

Kahneman, D., \& Deaton, A. (2010). High income improves evaluation of life but not emotional well-being. Proceedings of the National Academy of Sciences, 107(38), 16489-16493.

Kamman, R., \& Flett, R. (1983). Affectometer 2: A scale to measure current level of general happiness. Australian Journal of Psychology, 35(2), 259-265. 
Kashdan, T. B., Biswas-Diener, R., \& King, L. A. (2008). Reconsidering happiness: The costs of distinguishing between hedonics and Eudaimonia. The Journal of Positive Psychology, 3(4), 219-233.

Kwon, P., \& Hugelshofer, D. S. (2010). The protective role of Hope for lesbian, gay, and bisexual individuals facing a hostile workplace climate. Journal of Gay \& Lesbian Mental Health, 14(1), 3-18.

Landeen, J., Pawlick, J., Woodside, H., Kirkpatrick, H., \& Byrne, C. (2000). Hope, quality of life and Sympton severity in individual with schizophrenia. Psychiatric Rehabilitation Journal, 23(4), 364-369.

Larsen, J., \& McGraw, A. P. (2011). Further evidence for mixed emotions. Journal of Personality and Social Psychology, 11(6), 1095-1110.

Lu, F. J. H., \& Hsu, Y. (2013). Injured athletes' rehabilitation beliefs and subjective well-being: The contribution of Hope and social support. Journal of Athletic Training, 48(1), 92-98.

Lucas, R. E., Diener, E., \& Suh, E. (1996). Discriminant validity of well-being measures. Journal of Personality and Social Psychology, 71(3), 616-628.

Lybbert, T. J., \& Wydick, B. (2018). Poverty, aspirations and the economics of Hope. Economic Development and Cultural Change, 66(4), 709-753.

Lyubomirsky, S., \& Lepper, H. S. (1999). A measure of subjective happiness: Preliminary reliability and construct validation. Social Indicators Research, 46(2), 137-155.

Magaletta, P. R., \& Oliver, J. M. (1999). The hope construct, will, and ways: Their relations with self-efficacy, optimism, and general well-being. Journal of Clinical Psychology, 55(5), 539-551.

Mähönen, T. A., Leinonen, E., \& Jasinskaja-Lahti, I. (2012). Met expectations and the well-being of diaspora immigrants: A longitudinal study. International Journal of Psychology, 48(3), 324-333.

Marques, S. C., Lopez, S. J., \& Mitchel, J. (2013). The role of hope, spirituality and religious practice in adolescents' life satisfaction: Longitudinal findings. Journal of Happiness Studies, 14(1), 251-261.

Martin, A. M. (2011). Hopes and dreams. Philosophy and Phenomenological Research, 83(1), 148-173.

Miller, J. F., \& Powers, M. J. (1988). Development of an instrument to measure Hope. Nursing Research, 37(1), 6-10.

Moriwaki, S. Y. (1974). The affect balance scale: A validity study with aged samples. Journal of Gerontology, 29(1), 73-78.

Nunnally, J., \& Bernstein, I. (1994). Psychometric theory. New York: McGraw-Hill.

Ojala, M. (2012). Hope and climate change: The importance of hope for environmental engagement among young people. Environmental Education Research, 18(5), 625-642.

Ong, A. D., Edwards, L. M., \& Bergeman, C. S. (2006). Hope as a source of resilience in later adulthood. Personality and Individual Differences, 41(7), 1263-1273.

Peer, E., Brandimarte, L., Samat, S., \& Acquisti, A. (2017). Beyond the Turk: Alternative platforms for crowdsourcing behavioral research. Journal of Experimental Social Psychology, 70, 153-163.

Petersen, A., \& Wilkinson, I. (2015). Editorial introduction: The sociology of hope in context of health, medicine, and healthcare. Health, 19(2), 113-118.

Phillips-Salimi, C. R., Haase, J., Kintner, E. K., Monahan, P. O., \& Azzouz, F. (2007). Psychometric properties of the Herth Hope index in adolescents and young adults with Cancer. Journal of Nursing Measurement, 15(1), 3-23.

Reichard, R. J., Avey, J. B., Lopez, S., \& Dollwet, M. (2013). Having the will and finding the way: A review and meta-analysis of Hope at work. The Journal of Positive Psychology, 8(4), 292-304.

Ryan, R. M., \& Deci, E. L. (2000). Self-determination theory and the facilitation of intrinsic motivation, social development, and well-being. American Psychologist, 55(1), 68-78.

Rustoen, T., Cooper, B. A., \& Miaskowski, C. (2010). The importance of Hope as a mediator of psychological distress and life satisfaction in a community sample of Cancer patients. Cancer Nursing, 33(4), 258-267.

Satici, S.A. \& R. Uysal (2016). Psychological vulnerability and subjective happiness: The mediating role of hopelessness. Stress and Health. Advance online publication. https://doi.org/10.1002/smi.2685.

Schimmack, U., \& Oishi, S. (2005). The influence of chronically and temporarily accessible information on life satisfaction judgments. Journal of Personality and Social Psychology, 89(3), 395-406.

Schwartz, R. H., \& Post, F. R. (2002). The unexplored potential of hope to level the playing field: A multilevel perspective. Journal of Business Ethics, 37(2), 135-143.

Sheehan, K. B. (2017). Crowdsourcing research: Data collection with Amazon's mechanical Turk. Communication Monographs, 85(1), 140-156.

Shek, D. T. L. (1993). Measurement of pessimism in Chinese adolescents: The Chinese hopelessness scale. Social Behavior and Personality, 21(2), 107-120.

Shorey, H. S., Little, T., \& Rand, K. (2009). Validation of the revised Snyder Hope scale (HS-R2): The will, the ways, and now the goals for positive future outcomes. Working Paper.

Sisask, M., Värnik, A., Kõlves, K., Konstabel, K., \& Wasserman, D. (2009). Subjective psychological well-being (WHO-5) in assessment of the severity of suicide attempt. Nordic Journal of Psychiatry, 62(6), 431-435. 
Sleat, M. (2013). Hope and disappointment in politics. Contemporary Politics, 19(2), 131-145.

Smedema, S. M., Chan, J. Y., \& Phillips, B. (2014). Core self-evaluations and Snyder's Hope theory in persons with spinal cord injuries. Rehabilitation Psychology, 59(4), 399-406.

Snyder, C. R. (2000). The past and possible futures of hope. Journal of Social and Clinical Psychology, 19(1), $11-28$.

Snyder, C. R. (2002). TARGET ARTICLE: Hope theory: Rainbows in the mind. Psychological Inquiry, 13(4), 249-275.

Snyder, C. R., Harris, C., Anderson, J. R., Holleran, S. A., Irving, L. M., Sigmon, S. T., Yoshinobu, L., Gibb, J., Langelle, C., \& Harney, P. (1991). The will and the ways: Development and validation of an individual-differences measure of hope. Journal of Personality and Social Psychology, 60(4), 570-585.

Van Boven, L. (2005). Experientialism, materialism, and the pursuit of happiness. Review of General Psychology, 9(2), 132-142.

Veenhoven, R. (2000). The four qualities of life. Journal of Happiness Studies, 1(1), 1-39.

Velting, D. M. (1999). Personality and negative expectancies: Trait structure of the Beck hopelessness scale. Personality and Individual Differences, 26(5), 913-921.

Watson, D., Clark, L. A., \& Tellegen, A. (1988). Development and validation of brief measures of positive and negative affect: The PANAS scales. Journal of Personality and Social Psychology, 54(6), 1063-1070.

Webb, D. (2007). Modes of hoping. History of the Human Sciences, 20(3), 65-83.

Wnuk, M., Marcinkowski, J. T., \& Fobair, P. (2012). The relationship of purpose in life and Hope in shaping happiness among patients with Cancer in Poland. Journal of Psychosocial Oncology, 30(4), 416-483.

Yalçin, I., \& Malkoç, A. (2015). The relationship between meaning in life and subjective well-being: Forgiveness and Hope as mediators. Journal of Happiness Studies, 16(4), 915-929.

Youssef, C. M., \& Luthans, F. (2007). Positive organizational behavior in the workplace: The impact of hope, optimism, and resilience. Journal of Management, 33(5), 774-800.

Ziv, N., Chaim, A. B., \& Itamar, O. (2011). The effect of positive music and dispositional hope on state hope and affect. Psychology of Music, 39(1), 3-17.

Publisher's Note Springer Nature remains neutral with regard to jurisdictional claims in published maps and institutional affiliations. 